\title{
Childhood and the Child as a Subject of Philosophical and Cultural Reflection
}

\author{
Diana Ivanovna Mamycheva \\ Vladivostok State University of Economics and Service \\ Email: mamycheva@yandex.ru
}

\author{
Doi:10.5901/mjss.2015.v6n3s6p211
}

\begin{abstract}
The article discusses the theming of childhood and child figures in the works of philosophers in different historical periods; analysis of the historical volatility of ways to describe his childhood on the basis of reflective experience of the meaning of human existence, having started in the real or symbolic act of birth, shows the importance of building up the meaning of the figure of a child for subjectivation. The possibility of an authentic understanding of childhood is associated with the need to selfdetermination, that is, looking at the definition of a child or talking about him as someone who had some expectations, a temporary experience, that is enclosed in a space of some eventful horizon which directs the power of vision.
\end{abstract}

Keywords: child, childhood, philosophy, culture, reflection, Natal, generative communication.

\section{Introduction}

An important sign of a number of cultural events in favor attention to the figures of the child and childhood that allows you to see the nature of cultural interest, reasons that go beyond a purely instrumental and positivist. It seems that this promise vnepozitivistsky associated with such philosophical trends that determined the horizon of modern thought of the subject, as the phenomenology of Husserl, Heidegger's fundamental ontology, psychoanalysis Sigmund Freud. It is these fundamental philosophical projects in comprehending the new foundation of the European human subjectivity, allow a shift from concern desire structuring, organizing and shaping the child, embodied in social projects and cultural policies in the individual body. To the attention of the actual questions of ontology, the nature of being a child and the reasons that make this phenomenon of existence. Way paved data philosophical project leads to such landmarks as the daily, beingwith-others, communication, personal history, creating the foundation for other systems of relations and thoughts.

It seems that the philosophical perspective reflection theme of childhood serves as an alternative to traditional expansion and psycho-pedagogical approach, centered mainly on the issues of socialization and optimization of the growing subject, the child as an agent of instrumental effects, and a child - as a kind of "simulator" for optimizing skills. While childhood and child appear much more complex phenomena, the understanding of which depends both on the intellectual erudition and personal culture.

The increasing complexity of the inner reality of the modern man discovered the complex nature of language, image, action inevitably turns the search for a stable base, whose presence is carried out by building individual stories (Ovchinnikov A.I., Mamychev A.Yu. \& Mamycheva D.I., 2015). And in this history of childhood - one of the fundamental issues. With this sense, the complexity of reflection childhood correlated with the philosophical theming, naturally, his comprehension of the force conjugate becomes existential event. It seems that in many ways it is this latent motive is the basis and allows to understand the variety of embodiments in which the theme of childhood clothed.

A variety of approaches and analytical procedures give a picture of the complexity, volume and depth of knowledge of modern childhood. Appeal to the approaches and ways of thinking about childhood themes as part of everyday life, the fact of their own history, the base of social order, teleological motif of questioning, the artistic image makes it possible in a variety of approaches to discover their individual childhood project that, in fact, implement the ability to be a modern subject.

\section{Literature Review}

Currently subject and conceptually crystallized cultural, anthropological, psychological and pedagogical approaches to the understanding of childhood, but his main idea they are based on the idea of the need to expand the analytical philosophical adequate child theming, and this measurement is fundamental to the scientific understanding of the 
problem. Analytical literature on humanitarian reflection of childhood and child figures can be grouped in the following areas.

Firstly, it is the historical and philosophical works, among them are the ones in which references to the child and the child is not the main subject of interest, and is illustrative or metaphorical. Such certificates are important as a significant historical and philosophical source. There may be mentioned thinkers like Heraclitus, Plato, Aristotle, St. Augustine, Abelard, Aquinas, Michel de Montaigne. The first proper philosophical systematization of the teachings of childhood belong to Kant, I. Fihte, L. Feyerbahu. Reflections S. Kerkegora, Nietzsche, Jean-Paul Sartre, M. Heidegger, actualized the experience of early memories of childhood as an existential drama. Continued philosophical reflection in the prism of his childhood relationship with an adult, first opened the world of a child, M. Buber, E. Levinas. Russian philosophy in the face of Berdyaev, S.N. Bulgakov, V.V. Zenkovsky, Ivan Ilyin, V.V. Rozanov et al. Developed under the influence of the orthodox doctrine of childhood as a subject of parental care duties of man towards to the plan of God.

Secondly, philosophical works, to comprehend the changes axiology and ontology childhood in the modern thought, the Western: H. Arendt, Zh. Lakan, H. Shues, Michel Foucault. Domestic: A.A. Gryakalov, T.V. Schittsova. The result was a domestic methodological turning direction - the philosophy of childhood, marked V.V. Grechannym, E. Zolotuhinoy-Abolin, A.P. Mozelovym, E.G. Sokolovym, N.S. Yulinoy et al.

Third, study abroad anthropology, classical examples of research childhood steel works L. Levy-Bruhl, L. LevyStrauss, M. Mid. Domestic anthropological studies of developing socio-cultural paradigm of certainty of childhood as a time of increased concern on the part of adults, among them - A.I. Azarov, T.A. Bernshtam, N.A. Butinov, S.D. Domnikov, O.E. Kosheleva, L.S. Lavrenteva, E.V. Revunkova, A.V. Sergeeva, E.S. Soboleva, I.I. Shangina and others. In this tradition appeared semiotic study of imagery and language of the child's game S.B. Adonevoy E.A. Pokrovskogo M.P. Cherednikovoy, Yu.V. Ekkemeevoy; cultural reconstructions of children's folklore A.F.Belousova, V.A. Vasilenko, G.S. Vinogradova, O.N. Grechinoy, M.V. Osorinoy, O.I. Kapitsy.

Fourth, the major contribution to the understanding of childhood as a social phenomenon have work A.G. Kislova, E.A. Kurulenko, E.M. Rybinskogo, D.I. Feldshteyna, S.N. Scheglovoy. Unprecedented in its culturological significance are works Kon, who was one of the first in the Russian philosophy of culture has overcome the narrowness of the psychopedagogical measurement childhood and opened it as a historical reality, znakovo- symbolic world, the product of social relations that requires understanding in terms of identity phenomenal, equality.

Fifth, the modern transformation of childhood are devoted K. Kalvert, L. de Mais, B. Hakavalt, D. Herlihi, S. Shahar et al., Dedicated. Certain aspects of individualization childhood presented P. Byuhner, H. Tsaher, developed the concept of emancipation childhood U.Bekom, H.Popittsem. In the context of the crisis of culture and leveling of the boundaries between childhood and adulthood study presented M. Vinnsa, N. Postmana, D. Rihtera, H. Hengsta.

The resulting object field study of the phenomenon of childhood has numerous gaps, one of which was the result of leveling the anthropological ideal, certain value-semantic peculiarity of European culture that seeks to consolidate the beginning of human personality in his childhood, adult postulated on the basis of the characteristics of his early life history. The reflexive return to childhood constitutes the essence of the socio-cultural identity in various discourses about the child as a special type of person.

\section{The Methodological Base of Research}

The methodological base of research is based on the fundamental provisions of the philosophical and cultural science, determining the semantic context of description and explanation of childhood as a cultural phenomenon. The interdisciplinary nature of the research problem, thematizes childhood in discourses of philosophy, cultural studies, anthropology, makes the selection of appropriate methods of knowledge, leading to an understanding of patterns and relationships of cultural phenomena that affect the constitution of the historical volatility of the image of the child.

The regulators used as a methodological principles of historicism, system-structural analysis, modeling and theoretical reconstruction of social processes in culture. Scientific methods - synchronous, diachronic, and others. Used in connection with the description and explanation of the images of childhood in the context of Western European philosophical and scientific humanitarian thought. Historical and retrospective aspects of research childhood led to the generalization of research methods chronotop culture Bakhtin, dialogic V.S. Bibler cultural, historical anthropology A.Ya. Gurevicha. Accessing the sources in ethnology, folklore, semiotics, psychoanalysis determined the choice of the methods tested in the foreign studies: F. Aresa, M. Mid, L. Demoza, Freud, Jung, in the work of Russian experts: A.G. Kislova, E.M. Rybinskogo, S.N. Scheglovoy. 


\section{Results and Discussion}

At the European philosophical tradition of the first attempt to objectify meaning categories "child" belongs to Heraclitus, saying that: "Eternity is playing Child, which puts the Checkers: the kingdom (of the world) belongs to the child" (preSocratics, 1999, p. 295), has a sense of being a metaphor . But Plato solved quite urgent social problems of childhoodrelated foundations of the ideal state. He justifies the need to compensate for childbearing death snatched the lives of citizens of the policy and takes care of their education in special circumstances, outside the family, and the mother, which can spoil, spoil the child his affection. The main reason that defines this approach - a task to pursue the objectives sort goal state, and did not answer at all in some senses of its citizens. Achieving this goal justifies and infanticide against the sick and handicapped babies. The issue of childhood in ancient culture largely closed to the problems of education of obedient citizens, artists will of the authorities. Plato in the "State", we read the following statement: "Even our children have to play as much as possible comply with the laws, because if they become erratic and children do not follow the rules, you can not grow out of them serious law-abiding citizens" (Plato, 1971, p . 78). With seven years, the government takes care of the formation of moral and physical appearance of their citizens. And the nature of the adoption of a child in the culture is determined by the degree of its proximity to the desired ideal, and as the most malleable in education during youth, early childhood was not considered worthy of attention. Already here is made look at childhood as a subordinate, dependent, where the main criterion for social approval is the extent to which adult specimen. Especially strongly developed in antiquity with the child of the adult in terms of utility, for example, the father of medicine, Hippocrates, and the founder of gynecology Soran Efesky discussing what exactly newborns deserve to be grown.

In medieval philosophy, under the influence of the Christian doctrine of the sinfulness of man, childhood is interpreted in two ways. On the one hand, the child born will inherit the original sin, and in this sense it is no different from adults, which can be seen in the text of the "Confession" Aurelius Augustine - "I was shapen in iniquity, and in sin my mother nourished me in the belly" (Augustine 1994, p. 12), and the "innocent babies in their bodily weakness, not his soul." On the other - the child is understood as a symbol of salvation, a prisoner in the image of Christ-child, but such a view was cut off from the real, everyday life and therefore is not widely used in the national outlook. The binary connection of the sacred and the mundane chronotop in Christian culture affected the antinomy childhood in church and religious traditions of his understanding and presentation of it at the national, profane thinking, stereotyped child as inferior, immature physically, mentally, socially, and other human relations. Sacralization childhood is the result of the deification of human nature of Christ as a baby at the same time it has a metaphysical meaning most sinless period in human life, pure and naive perception of the world.

Daily routine childhood perception distorts his sacred idealization. Most profane mentality is influenced by the comic, the start of carnival in the culture in which a child brings a smile, touched by the contrast and difference from adult behavior, communication, language. In the popular perception of the world "inferiority" of the child exaggerates and paraded and childhood itself is associated with laughter and joy.

Changes in the degree of emotional, sensual-sentimental attitude towards the child come to the XVI century. while the spread of the ideas of humanism. This change is reflected in the works of thinkers to reinterpret the significance of the child. For Alberti in his treatise "On the Family" he notes that, on the one hand, the duty of every family play children continue their family, on the other, - he pointed out that children bring joy to their parents. Erasmus expresses even more positive about the child, noting that it is a value, which is more expensive in humans is almost nothing. The duty of man to reproduce and raise children $\mathrm{E}$. Rotterdamsky believes that feature which distinguishes man from the animal, and in which he likened to God. In addition, the educator criticized unilateral, in his view, related to the child when the parents are trying to see the children only physically complete. He calls his contemporaries to develop mentally and spiritually a child, so that, in conjunction with a physical full and achieved perfection of the individual.

Reflections M. Montenya also reflect the gradual evolution of morals in relation to the child. For example, he writes: "We should not think that talking about childhood, we are talking about something insignificant; on the contrary, and I will show here is that the state, which many consider unworthy of attention, really delicious". And at the same time it belongs to the following statement: "I, for one cannot feel the passion that, by virtue of which we kiss newborn still deprived of certain physical or mental qualities, they are able to make us self-love" (Montaigne M., 1998, p. 455). Otherwise compared to modernity was and look at the child's death. Montaigne says about this: "I myself have lost two or three children, although in its infancy, if not without some regret, then, in any case, without grumbling" (Montaigne M., 1998, p. 218). Sensual tolerance of child deaths corresponded not only mental, mental peculiarities of the era, but it was in relation to the general level of human health and especially children. Besides death and life were seen as a manifestation of God's will, to overcome the serious anguish and suffering.

Improving the general background of life and human health in the Enlightenment, and the change of ideological 
paradigms have led to the formation of a new view of the child, which is gradually becoming the main object of education, moral edification, education, which required understanding of its nature, the essential differences from the adult. In philosophy Dzh.Lokka, the child acts as a tabula rasa - a blank slate on which experience gets his drawing, describing the unique, individual person. Accordingly, the role of teachers and educators, who became responsible for the spiritual, social, mental, filling the soul of the child. However Zh. Zh. Russo understand the role of different education and training in the filling of the primordial experience of the soul of the child, pointing to the possible negative consequences of such an impact, "A child is born good savage, vicious society makes it."

Significant changes in the philosophical conceptualization of childhood occur after the publication of the works of Kant's pragmatic anthropology, in which he drew attention to the earliest period of human life - childhood, discovering it determines human nature feeling of freedom. The ability of a child after a few months of life, insist on, to show his will, according to Kant, the evidence "vague idea (or a similar her performance) on freedom and on the limitation of it, i.e., of injustice". "Scream, which publishes a newborn, not mournful and indignant and angry; he shouts no pain, and vexation, probably because he wants to move and his inability to feel like this is something chilling him, depriving him of his liberty ... "( Kant I., 1966, p. 587). Thus, the child is conceived as a human being, from birth has a predisposition to the manifestation of free will, which is then sent to the power of the mind to the knowledge of the world.

By the mid-end of the XIX century. the phenomenon of child acquires a visible outlines the theory and practice of education and philosophy is reflected in the number of schools and directions, among which are life philosophy, existentialism, Marxism, psychoanalysis. According T.V. Schittsova in childhood existentialism measured category "birth", which points to the primacy of being as such (Schittsova T.V., 2006). In the philosophy of childhood S. Kerkegora referred paradigmatic part of life, while adulthood - its syntax, as childhood tend primordial perception of the world is not yet burdened idols of consciousness. To appeal to the adult is naive, according to Kierkegaard, "the audit universally human," the revision of basic ("primitive") questions: "what it means to be human", "Are you and I are human beings," etc. The fundamental nature of these issues due to their role in the self-determination of the individual. In this sense, a return to the simplicity of children's perception of the world, according to Kierkegaard, there is a finding of identity, uncomplicated self.

Major social thinker, an informed natal (birth) as the image category fact of decisive importance for the understanding of social life appeared H. Arendt. "People - emphasizes Arendt - were not born to die, but, on the contrary, to start something new» (Arendt H., 1960, p. 242). New beginnings and it is in its original meaning of the concept postupaniya, considered along with the work and production as the main form of human activity. Natal or birth, defined in this case as "ontological premise for all could be something like postupanie» (Arendt H., 1960, p. 166). Arendt tries to link the metaphysical (and also political) existence of human birth, redefining itself ontological definition of man and the understanding of the fact of birth, which lead to a new perception of childhood.

Rehabilitation of the importance of the fact of birth for an individual carries and another German researcher $\mathrm{H}$. Shues. "If the birth as a unique event in the beginning of life in the world, believes the condition of possibility of intentionality, i.e., Natal - is an essential characteristic of every human being, thanks to which it can initiate the construction of meaning, the meaning of giving birth» (Schues Ch., 1997, p. 248). Thus, the connection is established and the birth smysloporozhdeniya. The very ability to be concretized as the ability to start. The man writes Shues, "should implement ... their natal, to be able to send itself constituting a way to something-like-something in intentional act." Birth and Natal acquire philosophical (ontological) loading in the light of the vocation to the birth of the subject.

Changing the setting that emphasizes pathos of birth as a condition of personal fulfillment and social implementation, makes it possible to "exit" from the philosophical "shadow" theme of childhood becoming an irreducible open to interpretation. Truth is found in childhood is that it serves as a starting point the "beginning" of the subject, the subject may be continued to find opportunities through birth, relationship birth and generation draws philosophical meaning look to source their objectification - the child. Thus, a necessary step in the consolidation of the ontological status of childhood, recognizing him as the meaning-culture is an ideological turn, marked by awareness of the importance of the fact of birth for the person as the conditions for the emergence of new meaning, and from there to the child and to his support.

See this movement of thought, expand its implicit direction allows an appeal to the concept of generative $\mathrm{E}$. Levinasa, the key point of which appear father-son relationship, wider - an adult and a child. Levinas, considering the question of the relationship of father and son, formulates the problem of renovation of the subject, generating itself from other subjective beginning in respect to which to overcome the isolation of the subject in itself, and in this - their own renewing rebirth. Philosopher examines the relationship of adult and child as a universal ontological structure, which implies that the attitude towards future generations is an essential factor in the constitution of the subject. "It was important showcased the - Levinas writes - that the other is not just the existence of the other, along with my freedom ... 
The coexistence of many freedoms - a multiplicity that does not affect the unity of each of them; or whether this multiplicity is united in one common will. And sexuality, fatherhood and death introduced into the existence of pairing, which deals with the act itself, the existence of each entity. The act-existence becomes guy "(E. Levinas, 1998, p. 101102).

The scope of experience, defined the concept in Levinas fertility reveals constitutive for being the subject of his act plural existence. Fertility - existential relationship between father and son - is, according to Levinas, the ability to identify itself with itself, while maintaining its own identity - an opportunity that opens up for the subject of "the infinite future." In "Time and the Other," and later in "Totality and Infinity" Levinas emphasizes that fertility should be understood as an ontological category. The very fruitful as being associated with the possibility of a new future beyond the factual limbs "I". Fertility is, for Levinas, the ratio for that future - the relation of father to son" ... . The Son - it was not me; and at the same time, I am my son ... my son be means to be the "I" in his own son, substantionally is in it, and at the same time not to be in it in an identical manner. Son plays the individuality of his father and at the same time remains external to the Fathe" (E. Levinas, 2000, p. 265-266) - describes Levinas dialectical relationship between father and son, opens a duality in the self-identity of the subject, ability in fatherhood" be different while remaining himself. "I'm looking for hypostasis, according to Levinas, the eternal return, which gives the person the awareness of the Self: The child is the most important argument appeals to him, so it should be equivalent and equal subject of an act of complicity. Consequently, self-adult requires for its determination of the friend who can be my equal-I and as such acts as a child. In addition, the concept of Levinas gets another embodiment of the intention of culture - Search update source, the conditions of the future, which causes theming childhood idea of a new culture.

In the Russian religious philosophy of childhood, first of all, to receive religious interpretation in the context of the idea of holiness, and is filled with a sense of the potential strength and actual weakness of man. For example, on this occasion Bulgakov says: "infirmity of the child in this world shows its power in the kingdom of heaven, worldly powerlessness - about God's help, dependency - of the supreme freedom, irrationality - of the highest wisdom. Hence, the natural innocence of a child, often burdened with only a sin of all mankind. Children are so innocent adults that they are "free from the bonds of morality." Childhood is all in the transcendental world, it is located "beyond good and evil," therefore do not apply to him categories of morality and moral adult.

Similar views held V.V. Rozanov, explaining that "the baby is positive in itself, ie, it is not only the absence of sin, but the presence of holiness. And in fact, you did not notice that the house in which you enter, - when he has no children, - gloomy and dark, it was spiritually dark, and playing with the children in it as something to glow, it is spiritual light" (Rozanov V.V., 1992, p.161). The image of the child has gone beyond the church rituals and symbols, becoming a beacon of everyday life, the purpose and meaning of everyday life Sisyphean labor. "So - continues V.V. Rozanov, because the house lights up children, he consecrated them, sanctioned in his being, in his work, in his care ... The baby awakens in us a sense of just what they left behind worlds, of which the freshness, brightness, as well as holiness, he carries his lips" (Rozanov V.V., 1992, p.162).

Modern philosophical line of perception of childhood as a metaphor for the beginning of life thanks to the work culture lined M.M. Bakhtina, V.S. Bibler, V.L. Rabinovicha. Without considering the specific phenomenon of childhood, they have opened the contours of contemporary cultural consciousness in a particular susceptibility to the whole than a man "thrown" to the beginning - the undertakings. "It's strange being in the world-to-world thinking designs thought to be thought, we for the first time (out) finds its language" (Bibler V.S., 1997, p. 52-53). Regulations in the "eve" of being with full confidence we can imagine the existence of childhood, philosophical theming uniqueness which is the basis of justification mirootkryvayuschey mission of the child.

The idea of "Eve" mating a first time-being, naive, surprise, simplicity is a metaphor for life in the context of childhood creativity V.L. Rabinovicha. Comprehending the miracle of creation, V.L.Rabinovich writes: "And all this - a child. Child bright-eyed, surprised his own - only pomyslennoy - audacity (God six days of creation); shaken by the word cat, so like most cat; and then - sculpts talk, gain experience in a no); Sun-Plunder things of the world as the world's first time in this instant set out to capture it all - I see and what I see, then I draw; or: How I hear, I say (lopochu, babbling, stamping, busily). Draw-malyuyu, zabudayu-burovlyu, pick-zabudayu, murmuring, muttering kalyakomalyayu, bumagomarayu ..." (Rabinovich V.L., 2002, p.120). The metaphor of "child god" is not accidental, that it explains the origin from which the universe is unfolding, going on the world, to create a culture. In this case, the naivety and simplicity "child of God" are symbols of ultimate, absolute complexity and diversity, which are thought potentially it. Like the Almighty God, the child (until he became an adult) can still all just for him there are no borders.

The other side of a difficult child naively revealed in the works T.V. Schittsovoy justifying the transcendent meaning of life in the culture of childhood. The situation on the border of childhood cultural topics as historically developed area of adults, according to Schittsovoy elevates pleasure to pytstvo, inquisitiveness of the principle in mind the principle of 
subjectivity being the child's existence. Thus, the pursuit of new, curiosity appear basic attributive properties childhood. Diagnosing the current state of culture, researcher says that modern generative community has a need to be updated, a new craving, which is the most authentic embodiment of childhood experiences of perception appears oprivychennyh, everyday meanings, updating, "ostranyayuschy" open them again.

This willingness to enter the adult and take the "circle of curiosity," akin to the initiation, the ability of the adult subject to the new-beginnings, creative rethinking culture actualizes the meaning of culture as a horizon unknown. "As a newborn does not have its (self-development) prospects" home of peace "and only a serial social genesis can make him a carrier of a cultural-historical topics at the beginning of his life as if the person is on the border of external and internal horizons on its border and stranger, speaking border, transitional figure par excellence. Transition ... in the transcendental sense that its inherent uncertainty of the horizon, the unique open-minded naivety being to the world is a condition for the possibility of a new institution of the world as a coherent field values. Transition is such an institution, and thus - the notion expressing the transcendent meaning of being a child, acting on this basis in the culture of adult paradigm of creative attitude to the world and his own self" (Schittsova T.V., 2006, p. 334). In view of unencumbered, nepropechatannosti typical values of their culture, the child, although the light is "within" are preset system normality expected in their regulations, may itself be characterized as "an area for projecting the unexpected."

By the turn of XX-XXI centuries. philosophy of childhood gained new methodological outlines, involving children in the discourse of the scientist and co-creation of the child. So a "philosophy for children" as a special program of humanistic development, whose founder within the Western scientific tradition made M. Lipman, and in Russia it was supported A.A. Gryakalov, A.G. Kislov, N.S. Yulina. For the philosophy of childhood characterized by "the establishment of the substantial features of the nature of childhood, but this substantiality, according A.A. Gryakalov, a special kind of it presents the experience together. The philosophy of childhood has to do with the ever-event-opening experience of existence "(Griakalov A.A., 2003, p.53). Philosophical reflection sees the baby the way it reveals the consciousness of an adult, and that, in turn, is exposed to the experience of belonging. This idea meets a response in thinking about the inevitability of death E. Levinas who is looking for her weakness in the existence of Eros and procreation. According to him, the child - it is an opportunity not to be our self to himself, to experience a sense of belonging, but not empathy. I'm looking for hypostasis, according to Levinas, the eternal return, which gives the person the awareness of the Self: The child is the most important argument appeals to him, so it should be equivalent and equal subject of an act of complicity. Consequently, self-adult requires for its determination of the friend who can be my equal-I and as such acts as a child.

\section{Conclusion}

Way of describing childhood as a cultural phenomenon reflects the variability of reflexive human experience in determining the beginning and the meaning of life at different stages of development of West-European humanitarian thought. The concept of childhood becomes philosophical meaning at the same time with the idea of the beginning of human existence in the culture as a creator of your life, determining the boundaries of birth and death. Human responsibility for their own childhood is made dependent on the desire of the individual to actualize the meaning of life and to transfer experience to future generations, to determine, therefore, the development of culture. Awareness of the importance of childhood as a potential resource of the progress of culture has defined the philosophical content of the theories of socialization and enculturation, enhance and consolidate the axiological sense of childhood.

The phenomenon of childhood in the culture exposed to prevailing attitudes, patterns of perception as the human stage of preparation for adult life, inclusion or exclusion of symbolic reality existing discourses. Absence of childhood as a meaning-culture phenomenon mediates undeveloped ideas about him, leveling a unique children's language as a semiotic system, the authorization of child abuse until infanticide. The manifestation of childhood in life conditions sotsikulturnoy establishment discourse that determines its value and meaning and place in the hierarchy of relationships with other entities culture assigns to them a set of rights, legalize the life and liberty of the child.

Increased attention to childhood as a period of preparation for adult life a person is found in Christianity, which opens this phenomenon in connection with cult Infant Jesus. The overthrow of the natural essence of man as a sinful creature raises the earliest age when the devastating effects of physical affection have not yet led to the spirit and soul of the person's death. Culture and philosophy of modernity focuses childhood in measuring social qualities necessary for a person to be acquired by him in the course of social interactions, and turns it into a phenomenon of increased concerns of the older generation of younger, which is reflected in changes in the language of the child and adult. Further childhood desire to subordinate the existing norms, values and ideals of the culture with the aim of advancing age the pace of social and cultural adaptation of the child caused a shift of the boundaries of childhood, his emancipation and sovereignization in the status of a full subject of social and cultural interactions. A fundamental change in thinking about childhood as the 
most important period of development of the individual, cause any changes in the culture originated in Western European science by the end of XIX - early XX centuries.

A necessary step in the consolidation of the ontological status of childhood, recognizing him as the meaningculture is an ideological turn, marked by awareness of the importance of the fact of birth for the person as the conditions for the emergence of new meaning, and from there to the child and to his support. The self-consciousness of an adult requires for its determination of the friend who can be my equal-I and as such acts as a child.

\section{References}

Augustine. (1994) Confessions. M.

Bibler, V.S. (1997) On the sides of logic culture. Book selected essays. Russian phenomenological society. M.

Bulgakov, S.N. (1994) with the unfading Light: contemplation and speculation. M.

Griakalov, A.A. (2003) Philosophy and transpedagogika // Innovation and childhood education. Collection of conference materials. A series of "Symposium", Issue 29. St. Petersburg.

Pre-Socratics. (1999).

Kant, I. (1966) Anthropology from a pragmatic point of view. Works in 6 vols. V.6. M.

Levinas, E. (2000) Favorites: Totality and Infinity. M-SPb.

Levinas, E. (1998) Time and the Other. M-SPb.

Montaigne, M. (1998) experiments. The 3 books. Kn.2. St. Petersburg.

Plato. (1971), Collected Works in 3 vols. V.3. M.

Rabinovich, V.L. (2002) Kalyaka-Grafik Seventh Day / language of culture: Interactions. M.

Rozanov, V.V. (1992) Religion. Philosophy. Culture. M.

Schittsova, T.V. (2006) Momento nasci: Community and generative experience (Study of existential anthropology). Vilnius: YSU Moscow.

Arendt, H. (1960) Vita active. Oder vom tatigen Leben. Stuttgart.

Kennedy, D. (1992)The hermeneutics of childhood // Philosophy today. - Celina, Vol. 36, N 1.

Kirsanova, L. \& Korotina, O. (2015) History as an ideology // Mediterranean Journal of Social Sciences Vol. 6, No. 3, May 2015 Rome, Italy.

Ovchinnikov, A.I., Mamychev A.Yu. \& Mamycheva D.I. (2015) Socio-cultural foundations of coding state-legal development /I Mediterranean Journal of Social Sciences. Vol. 6, № 3

Postman, Neil. (1994) The Disappearance of Childhood. New York: Vintage Books, a division of Random House, Inc.

Schues, Ch. (1997) The birth of Difference. Halb-Bd. 1997.

Waksler, F.C. (1986) Studying children : Phenomenological insights // Human studies. Dordrecht etc., Vol. 9, N 1. 
